\title{
Tortas holandesas: patrimônio cultural de Carambeí (PR)
}

\author{
Netherlands: Carambeí (Paraná, Brazil) cultural heritage
}

\author{
Layane de Souza OnOFRE ${ }^{1}$ \\ Leonel Brizolla Monastirsk ${ }^{2}$
}

1 Universidade Estadual de Ponta Grossa (UEPG). E-mail: layanesonofre@gmail.com

2 Professor associado do Departamento de Geociências da Universidade Estadual de Ponta Grossa e docente do Programa de Pós-Graduação em Geografia da mesma universidade. Atuante nas áreas de geografia social e cultural e geografia histórica (memória social, patrimônio cultural, história da cidade, planejamento urbano e turismo).E-mail: leonel@uepg.br

\begin{abstract}
A comida representa simbolicamente um grupo social. Por meio dela é possível conhecer e reconhecer o modo de vida, costumes de gerações, alimentos preferencialmente utilizados, os que se tornaram típicos e que revelam determinadas sociedades. Este estudo tem interesse em reconhecer a etnia holandesa por meio das tortas, atividade cultural e alimentar que nos últimos anos incrementou a realidade de Carambeí, Paraná, Brasil, pois a cidade, assim como outros locais brasileiros, teve colonos holandeses, e estes introduziram a prática das tortas. Apesar de o surgimento das tortas apresentar algumas histórias contraditórias, é indiscutível que traduz a realidade de um grupo social, que revela e preserva seus costumes. O que este estudo busca é analisar a cultura de um povo pela comida, sendo esta uma de suas representações, como as pessoas entendem essa repercussão das tortas, atreladas ao fator histórico de simbologia, que faz parte da memória e identidade local, em ênfase, a opinião sobre as tortas enquanto patrimônio cultural imaterial. Atrelado a esse patrimônio existe o "saber fazer" das torteiras, que argumentam que essa prática está associada aos costumes dos imigrantes e do lugar, ligada também ao acesso das receitas, memória coletiva, cultura e identidade. Pelas análises e explanações é possível indicar as tortas como constituintes de um patrimônio cultural imaterial do lugar, vinculado e legitimado pela atividade turística.
\end{abstract}

Palavras-chave: tortas holandesas, patrimônio cultural, Carambeí.

Food symbolically represents a social group, through which is possible to know and recognize the way of life, customs of the generations, foods preferably used, and the ones that have become typical and reveal certain societies. This work takes interest in recognizing the Dutch ethnicity through pies, cultural food activity that over the last years incremented the reality of Carambeí, Paraná, Brazil. This city, as other Brazilian places, hosted Dutch colonists who introduced the practice of pie making. Although the emergence of the pies presents some contradictory stories, it is undisputed that it translates the reality of a social group, revealing and preserving their customs. This study aims at analyzing the culture of a people by their food, being that it is one of their representations; how people understand this repercussion of the pies, connected to the historical factor of symbology, which is part of the local memory and identity; and with emphasis on the opinion about the pies as immaterial cultural heritage. Linked to this heritage, there is the "know-how" of pie-makers, who argue that this practice is associated to the customs of the immigrants and of the place, also tied to the access to recipes, collective memory, culture and identity. By means of analyses and explanations it is possible to indicate the pies as constituents of immaterial cultural heritage of the place, bound and legitimized by the tourism activity.

Keywords: tortas holandesas, cultural heritage, Carambeí. 


\section{INTRODUÇÃO}

A cidade de Carambeí (PR) foi formada inicialmente por brasileiros, indonésios e holandeses, em busca de novas terras e oportunidades. Entretanto, recebeu mais holandeses, devido à densa migração ocorrida em 1911, que configurou a cidade, permanecendo suas tradições e hábitos até os dias de hoje. Foi reconhecida primeiramente na arte da produção leiteira, pela Cooperativa Holandesa de Laticínios, antecessora da marca nacionalmente reconhecida Batavo. Nos últimos anos, os olhares se viraram para outra técnica alimentar, as tortas holandesas. O surgimento delas apresenta algumas histórias contraditórias, entretanto, é indiscutível que traduz a realidade de um grupo social, que revela e preserva seus costumes.

Outro fator norteador de povoamento da cidade é a influência da Brazil Railway Company. Essa companhia ferroviária adquiriu uma fazenda na região em 1909 com o objetivo de assentar colonos na pecuária e na agricultura, visando ao futuro transporte dos produtos pelas ferrovias que ligavam Ponta Grossa à cidade portuária de Paranaguá e aos estados de São Paulo, Santa Catarina e Rio Grande do Sul. Castro Kooy (1986, p. 12) descreve que "[...] visitou a colônia e ficou entusiasmado, logo vendeu sua propriedade e se mudou para Carambeí, no dia 29 de março de 1911". Com a felicidade da família, nesses belos, imensos e produtivos campos, posteriormente, denominados Campos Gerais, o sr. Jan resolveu ir à Holanda, a fim de trazer mais imigrantes. Entretanto, não foi possível, mas mesmo assim Carambeí se tornou uma colônia holandesa, visto na Figura 1 com os primeiros imigrantes.

Os primeiros colonizadores de Carambeí se estabeleceram aqui porque a "Brazil Railway Company" tinha um plano de colonização para esta área onde possuía muitas terras. Seus planos eram conseguir uma produção agrícola para carga de seus trens. Foi no dia 4 de abril de 1911, que Leendert Verschoor, como primeiro holandês, aceitou fazer um contrato com a Companhia. Esta data pode ser considerada a data da fundação da colonização holandesa em Carambeí. (KOOY, 1986, p. 28).

Figura 1. Os primeiros imigrantes holandeses

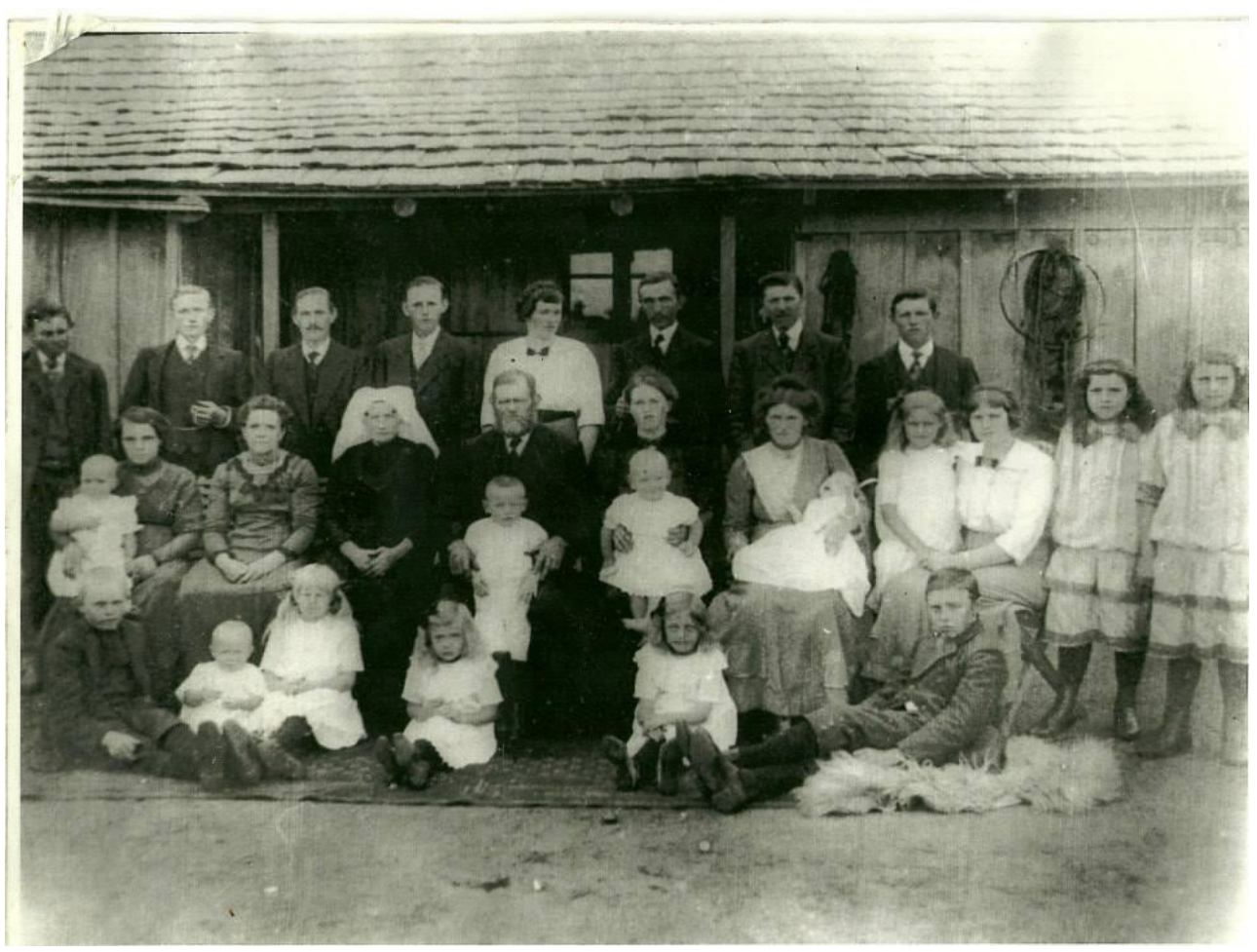

Fonte: Foto de autor desconhecido. Acervo: Parque Histórico de Carambeí (2014). 
Predominantemente holandesa, Carambeí chegou ao final do século XX como um dos poucos casos de sucesso entre as colônias criadas no Paraná. Referência tecnológica e exemplo a partir da experiência do cooperativismo, desmembrou-se de Castro e Ponta Grossa, tornando-se oficialmente um município em 13 de dezembro de 1995. A partir desse acontecimento regional, definitivamente gravou seu nome na história por meio de um belo exemplo de superação e de capacidade de resistência. (CHAVES, 2010, p. 101).

Assim, podemos ver que Carambeí se fez visível por ter sido construída e constituída predominantemente da cultura holandesa, por ser a sede da Cooperativa Batavo, e esses imigrantes depositaram na antiga colônia seu modo de empreender os negócios - capitalistas -, nas técnicas de trabalho, com suas características históricas e culturais, simbolismos, elos profissionais, familiares e, ainda, na forma harmoniosa que se relacionam com os nativos.

\section{A ALimentaÇão}

A estabilidade dos holandeses na antiga fazenda Carambehy desencadeou uma série de problemas e dificuldades, mas também definiu a presença e representação dos holandeses em terras brasileiras. Nos primeiros anos, os colonos tinham a alimentação composta de feijão preto com arroz, pão, queijo e mingau. As verduras eles mesmo plantavam - um direito oferecido pela Cia. Ferroviária, além das frutas - inicialmente aquelas conhecidas na Europa, como a laranja, pera e melancia. $\mathrm{O}$ uso do queijo, manteiga e leite no início era privado, pois desses produtos vinha o sustento da família.

Com o passar do tempo, os imigrantes holandeses foram materializando seus costumes, identidades e tradições no pequeno território. Dentre os elementos de identidade deles, as representações alimentares se tornaram muito reconhecidas e valorizadas por eles, pois buscaram através dela a manutenção da preservação e, por conseguinte, as sociabilidades que sustentam a sua cultura. Como indica Pereira (2011, p. 1137), a alimentação e as sociabilidades alimentares são vistas aqui como elementos ligados à cultura e à identidade do grupo imigrante holandês, e também como fatores de reforço e de especificação desta identidade. E ainda complementa: sociabilidades que constroem espaços de consumo de alimentos e bebidas, ritualizando o alimento e o inserindo em uma dimensão cultural, muito além do mero aspecto nutricional. (PEREIRA 2011, p. 1137).

Essa representação das culturas através do alimento se propaga a partir do século XIX, com a consolidação das imigrações de diversas etnias, levando para o novo destino novos ingredientes, conhecimentos e modos de preparar os alimentos, o que resultou na articulação entre alimento e identidade, que para Hall (1992, p. 10) identidade é algo que, desde o Iluminismo, se supõe definir o próprio núcleo ou essência de nosso ser e fundamentar nossa existência como sujeitos humanos.

"A comida é expressão da cultura não só quando produzida, mas também preparada e consumida" (MONTANARI, 2013, s.p). Assim as pessoas não apenas ingerem os alimentos, e sim criam técnicas e maneiras para melhor aproveitá-la, e a forma de como é comido também pertence a essa análise. Podemos conhecer determinados grupos pela sua maneira de lidar com os alimentos, de produzi-los e o modo de se comportar a mesa.

Como discorre Schlüter (2003, p. 13), "a alimentação é um processo consciente e voluntário que se ajusta a diferentes normas segundo cada cultura e, no qual o ser humano é socializado desde o seu nascimento". Ainda discorre que "diferentemente dos animais, o homem não só partiu para a caça e coleta, mas também aprendeu a cultivar plantas, criar

animais e cozer seus alimentos". (Ibidem, p. 19). A discussão remete Pereira (2011, p. 1) sustentando que "alimentação e as sociabilidades alimentares são vistas como elementos ligados a cultura e a identidade do grupo imigrante holandês, e também como fatores de reforço e de especificação desta identidade".

Destacam os estudiosos que a alimentação está assumindo cada vez maior importância, como mais um produto para o turismo cultural. As motivações principais encontram-se na busca pelo prazer através da alimentação e da viagem, mas deixando de lado o standart para favorecer o genuíno. A busca pelas raízes culinárias e a forma de entender a cultura de um lugar por meio de sua gastronomia está adquirindo importância cada vez maior. A cozinha tradicional está sendo reconhecida cada vez mais como um componente valioso do patrimônio intangível dos povos. Ainda que o prato esteja à vista, sua forma de preparação e o significado para cada sociedade constituem os aspectos que não se veem, mas que lhe dão seu caráter diferenciado. (SCHLÜTER, 2003, p. 11). 
A comida representa simbolicamente um grupo social, por meio dela é possível conhecermos e reconhecer o modo de vida, os hábitos e costumes de gerações, os alimentos preferencialmente utilizados, como lembrar o sul do país pelo churrasco e nordeste por comidas com fortes temperos. São alimentos que se tornaram típicos e revelam determinadas sociedades.

A cidade de Carambeí tem a sua cultura influenciada pelo alimento (presente nas "tortas holandesas" e produtos batavos), as tortas ficaram reconhecidas em grande escala nos últimos anos, passando as fronteiras territoriais das cidades ao entorno. Essa transformação do alimento pode mudar uma sociedade, dentro de certo tempo. Essa realidade caracteriza o lugar, pelas pessoas, suas experiências, memórias, além da culinária, "ela não marca apenas a passagem da natureza à cultura; por ela e através dela, a condição humana se define com todos os seus atributos". (LÉVI-STRAUSS, 2004, p. 197).

A alimentação pode representar um grupo social e ainda um "saber fazer", como um patrimônio cultural. Patrimônio não é só por uma intitulação ou registro da técnica, mas, o enraizamento simbólico de um povo, o seu pertencimento e/ou reconhecimento no lugar, onde transbordam os sentimentos de se sentir em casa, acolhido e ainda incluso a uma identidade social. As tortas já possuem uma história de mais de um século, uma prática que perdurou, tem uma simbologia forte, representa a cidade e ainda traz dividendos para esta.

Alguns grupos buscam a sua preservação pelo turismo. De modo que, com conhecimentos adquiridos da história, os modos de fazer passados de gerações, os rituais, festividades que os representam, sejam o principal atrativo, digamos um atrativo cultural.

Isso se faz visível em Carambeí, onde os moradores (holandeses ou não), guardando e praticando ainda os costumes, buscaram divulgar o seu cotidiano, um exemplo é o Parque Histórico, que reproduziu a antiga colônia e hoje se tornou um local de grande visitação, além da própria cidade, que esteticamente possui uma paisagem peculiar, um elo com a Holanda.

O turismo é definido como o deslocamento para fora do local de residência, realizado por motivo de lazer, descanso, cultura, religião etc.

Daí se verificar que o turismo é, antes de tudo, um fenômeno social que consiste no deslocamento - voluntário e temporário - de pessoas que pelos mais variados motivos, sejam ele de lazer, saúde, compras, descanso ou outro qualquer, saem de seu local de residência para outro, utilizando seu tempo livre (ócio), visando a satisfação de suas necessidades na vivência de novas experiências, no contato mais íntimo com a cultura, a sociedade local e com a natureza. (DIAS et al., 2009, p. 3).

Historicamente o turismo está entrelaçado aos aspectos naturais, sociais e históricos, de modo consequente aos patrimônios locais existentes. Porém o que vem tendo força é o turismo ligado à identidade de uma sociedade, que se conhece por meio da cultura (costumes, crenças, artes, história e gastronomia). Desenvolveu um cenário, uma perspectiva em que o turista se interessa muito mais por onde está, do que somente fazer sua visita, são elementos existentes, imbricados na viagem, sejam eles físicos e sociais que permutam o olhar do viajante, concretizando assim o ideário de turismo, que tem sua raiz nas manifestações patrimoniais, de estética natural ou cultural.

Com os anos houve um aumento da atividade gastronômica, as pessoas estão em busca do prazer da degustação, das mais variadas receitas, sendo uma forma de conhecer a cultura do outro, de entender as raízes de um lugar - assim, a cultura. No caso de Carambeí, isso se concretizou a partir do Festival de Tortas, que deixou a cidade mais visível, mais procurada pelo turismo, não só por seu aspecto histórico e cultural, mas principalmente pela gastronomia.

\section{PATRIMÔNIO CULTURAL IMATERIAL}

O uso do termo "patrimônio" surgiu em Roma e representava os bens deixados pelos pais aos filhos, bens esses materiais, como descrevem Pelegrini e Funari (2008, p. 26) "patrimônio em nosso quotidiano, surge como os bens de valor".

Ao passar dos anos, essencialmente o Cristianismo disseminou-o como uma maneira de preservar os símbolos, valores e sentidos imateriais, porém sua materialidade ainda existe até hoje, por exemplo, as edificações tombadas ou pela representação social simbólica.

Assim, todo ser humano tem sua cultura, configurada na adaptação com o meio em que vive, uma relação harmônica e muitas vezes não visível aos seus entre o ser e o meio e este meio ao próprio homem, mediante suas necessidades, modos de vida e pensamento. $\mathrm{O}$ patrimônio cultural 
é, portanto, resultado das relações sociais instituídas e incorporadas e capazes de expressar o que é mais precioso e singular ao coletivo. Enfim, as sociedades criam o seu patrimônio de acordo com as condições, realidades e interesses próprios. (CHAVES, 2011, p. 4).

Para Pelegrini e Funari (2008, p. 28), "o conceito de patrimônio cultural, na verdade está imbricado com as identidades sociais e resulta primeiro das políticas do Estado nacional e, em seguida, do seu questionamento no quadro da defesa da diversidade".

Patrimônio cultural em qualquer sociedade é sempre produto de uma escolha e, como toda escolha, tem um caráter arbitrário. Resulta da seleção de alguns elementos, enquanto outros seriam passíveis de esquecimento e destruição [...] o patrimônio cultural só pode ser entendido como um conjunto de símbolos. (CAMARGO, 2002, p. 96).

A noção de patrimônio cultural envolve os elementos fisicos, como, edificações, igrejas, museus, e os imateriais que são as representações festivas, danças, culinária etc., que dizem respeito ao patrimônio cultural imaterial.

Entretanto, a noção de patrimônio cultural imaterial tomou ênfase e foi assegurada após o Decreto 3.551, de 4 de agosto de 2000, que intitula o registro de bens imateriais e cria o Programa Nacional do Patrimônio Imaterial (PNPI). Esse patrimônio é incluso em um dos seguintes livros: I- Livro de Registro dos Saberes; II- Livro de Registro das Celebrações; III- Livro de Registro das Formas de Expressão e IV- Livro de Registro dos Lugares.

O patrimônio cultural imaterial representa uma construção social e coletiva, segundo a Constituição Federal de 1988, no artigo 216, constituem patrimônio cultural brasileiro, os bens de natureza material e imaterial, tomados individualmente ou em conjunto, portadores de referência à identidade, ação, memória dos diferentes grupos formadores da sociedade brasileira, nos quais se incluem.

Entende-se por 'patrimônio cultural imaterial' as práticas, representações, expressões, conhecimentos e técnicas - junto com os instrumentos, objetos, artefatos e lugares culturais que lhes são associados - que as comunidades, os grupos e, em alguns casos, os indivíduos reconhecem como parte integrante de seu patrimônio cultural. Este patrimônio cultural imaterial, que se transmite de geração em geração, é constantemente recriado pelas comunidades e grupos em função de seu ambiente, de sua interação com a natureza e de sua história, gerando um sentimento de identidade e continuidade e contribuindo assim para promover o respeito à diversidade cultural e à criatividade humana. (UNESCO, 2003, p. 4).

Essa caracterização sobre patrimônio cultural imaterial é referência mundial, como uma maneira de padronização e seguimento. São especificidades existentes em diversas localidades, cada uma com sua singularidade, costumes e representações, onde se torna visível aquilo que lhe representa.

Em Carambeí não foi diferente, contando com migração holandesa, especialmente, a partir do século XXI desenvolveu uma maneira de mostrar sua cultu$\mathrm{ra}$, mediante o reconhecimento das tortas, incluindo o Festival de Tortas, melhor apresentado no item seguinte. Essa medida foi tomada a partir de decisões públicas e por comerciantes. O que remete a se pensar na sua importância nesse tempo e espaço, incluindo a população, órgãos públicos e os estabelecimentos de torteiras. Essa iniciativa é recente, porém, teve grande repercussão na cidade e demais regiões.

\section{TORTAS HOLANDESAS ENQUANTO PATRIMÔ- NIO CULTURAL}

\author{
Carambei não é uma Holanda incrustada em solo brasileiro. \\ Tampouco é um pedaço de Brasil cedido aos holandeses. Ao \\ longo desses primeiros cem anos de existência, ela foi construída \\ a partir da realidade socioeconômica brasileira, constitui-se com \\ a ação empreendedora holandesa e contou com a colaboração de \\ outros grupos étnicos. Foi assim que se forjou em Carambei um rico \\ patrimônio cultural, resultado da mescla de diversas matrizes e de \\ sua elaboração a partir da realidade brasileira.
}

(CHAVES, 2010, p. 5).

Carambeí possui uma realidade peculiar e ao mesmo tempo comum, a inserção de uma etnia em outra terra, desempenhando características próprias e marcantes na história, junto com o modo de vida brasileiro.

Ao decorrer das leituras, notou-se que algumas pessoas seriam essenciais para a concretização da pesquisa, assim as análises se basearam nos questionários aplicados em Carambeí, via internet, e outro dedicado aos consumidores do Parque Histórico de Carambeí e Frederica’s Koffiehuis; 
torteiras, mulheres que fazem as tortas em Carambeí; criadora do Festival de Tortas, Suellen Pavanelo.

Foram perguntas como: Conhece as tortas holandesas? Já degustou? Acha que as tortas são um atrativo turístico? Considera as tortas como um patrimônio cultural de Carambeí? Esta última pergunta (GRÁFICO 1) retrata exatamente o objeto de estudo, obtendo respostas diversas, por exemplo:

Sim. De certo modo correspondem a um 'saber fazer', construção histórica de reafirmação constante entre os sujeitos que a produzem. (Informante 1, 2014). Com certeza, pois culinária também é cultura de povo. (Informante 2, 2014).

Sim, vejo como um patrimônio, pois em aspectos culturais o modo de viver e as práticas, neste caso a culinária, fazem parte das vivências dos moradores e que os turistas podem desfrutar. (Informante 3, 2014).

$\mathrm{Na}$ verdade, elas representam uma tradição holandesa, e não exatamente dos moradores de lá, apesar de ter habitantes holandeses. Não existem apenas as tortas 'holandesas’ em Carambeí. (Informante 4, 2014).

Sim, devido ao processo de colonização dos holandeses a cultura imigrante se enraizou e se interlaçou a cultura local fazendo do recorte um lugar único. (Informante $5,2014)$.

As tortas em si não, uma vez que as tortas não ficarão eternizadas, tendo uma consciência social sobre elas, acredito que talvez as receitas das tortas possam sim se configurar enquanto um patrimônio ligado à cultura neerlandesa, principalmente dos que se fixaram na região em Castro e Carambeí. (Informante 6, 2014).

Não sei se de Carambeí, mas das colônias holandesas. (Informante 7, 2014).

Não, é apenas um atrativo turístico para obtenção de renda para poucos. (Informante 8, 2014).
Gráfico 1. Tortas holandesas - patrimônio cultural imaterial?

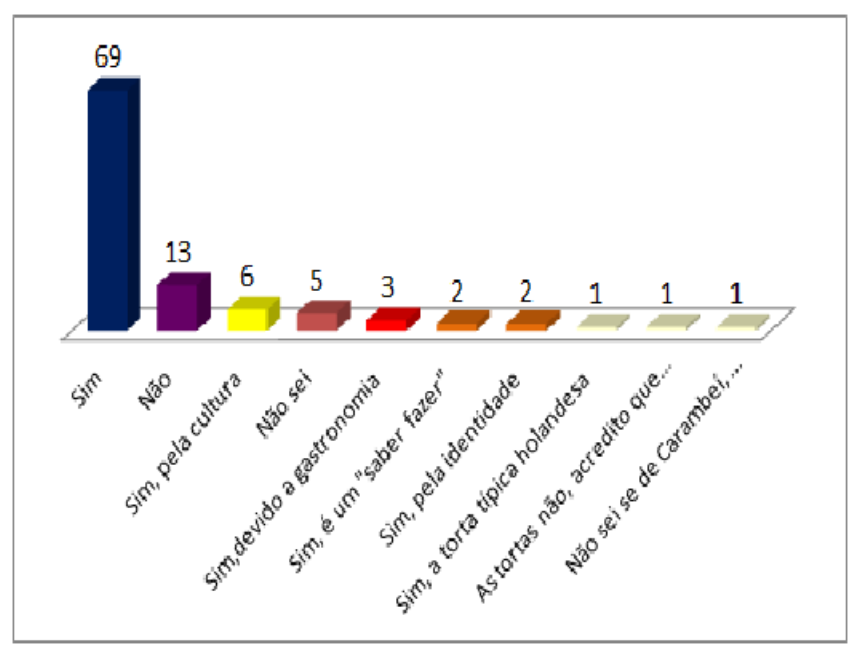

Fonte: Elaborado pela autora.

O patrimônio cultural imaterial é formado por um conjunto de elementos encontrados em determinados grupos sociais, que o diferencia e/ou os representa. São elementos como a dança, culinária, modos de fazer e arte, são aspectos representativos e de valoração.

O ter mo "patrimônio" vem sendo utilizado com frequência no cotidiano, ao se tratar, por exemplo, de patrimônio financeiro, econômico, de uma família, naturais, arquitetônicos históricos, culturais e intangíveis. O patrimônio oferece amparo para o entendimento da vida social e cultural de toda sociedade.

O patrimônio é usado não apenas para simbolizar, representar ou comunicar: é bom para agir. Essa categoria faz a mediação sensível entre seres humanos e divindades, entre mortos e vivos, entre passado e presente, entre o céu e a terra e entre outras oposições. Não existe apenas para representar ideias e valores abstratos e para ser contemplado. O patrimônio, de certo modo, constrói, forma as pessoas. (GONÇALVES, 2003, p. 27).

O patrimônio estende-se do privado, dos bens de uma família, de um sujeito, para algo coletivo, que mediante um sentimento de perda, dá conta de que era preciso salvar os vestígios, as tradições, ameaçados de destruição.

Um patrimônio não se justifica apenas por estar em registro, consiste em cada pessoa através de suas experiências, lembranças, modos de viver, nomear o "barzinho da esquina", a "mercearia do João", "a praçinha do bairro", é uma maneira pelas quais as 
pessoas se identificam e faz desse fixo um elemento marcado de simbolismo, que perdura no tempo, um sentimento de pertencimento ao lugar que consiste o indivíduo e o coletivo.

Em Carambeí, a cultura holandesa combinada com a brasileira construiu uma identidade específica, atrelada a elementos culturais e modos de vida, que assim constituem o patrimônio cultural, como concretizado no Gráfico 1. Para Possamai (2008, p. 207), "patrimônio cultural é garantia da sobrevivência social dos povos, porque é testemunho de sua

vida".

Pois bem, patrimônio cultural de um povo é composto no espaço, transpondo no tempo e manifestando suas raízes e traços históricos mantidos e adequados a dinâmica espacial. Sua preservação se faz necessária no âmbito de que com ela reconhecemos as diversas culturas existentes e ainda colabora com a própria sociedade de maneira econômica quando há o intuito turístico. São expressões importantes que devem ser conservadas em conjunto com sua divulgação, garantindo o conhecimento de futuras gerações e a legitimidade cultural.

\section{A REPRESENTAÇÃo CULTURAL DO "SABER FAZER"}

De acordo com o Decreto 3.551, de 4 de agosto de 2000, patrimônio cultural imaterial inclui o "saber fazer" de um povo, representado na cultura e modo de vida, que se transmite de geração a geração e busca se registrar no tempo.

Encontramos em Carambeí essa prática advinda das torteiras. É por meio da transmissão dessa prática que continua o hábito de fazer as tortas. Hábito este que se transpõe ao tempo, gerindo a cultura carambeiense.

A alimentação vai além das potencialidades nutricionais, retrata uma cultura. Por meio dela podemos compreender a história, os gostos e os hábitos. Essa configuração se iniciou em décadas antigas, com o encontro de alimentos em determinadas localidades e a inexistência em outras, assim, os indivíduos tiveram que se habituar aos alimentos disponíveis. Referente a esse assunto, Montanari (2013, p. 44) descreve:

A relação dos homens com o espaço, enfim, modificou-se radicalmente, ampliando-se até culminar na lógica da 'aldeia-global'. Hoje, nos países industrializados, é possível encontrar produtos frescos em todas as épocas do ano, empregando o sistema-mundo como área de produção e de distribuição.

Com essa modificação descrita por Montanari (2013) encontramos produtos em dispersos locais, inseridos nas diversas culturas. Esse sistema ajudou na criação dos pratos. Ao pensar nas tortas holandesas, por meio deste estudo, tivemos a informação de que foram feitas pela primeira vez em Carambeí, porém as encontramos em várias cidades, porém, o que muda é a receita e seu saber-fazer, vistas nas figuras 2 e 3.

Figura 2. Torta holandesa.

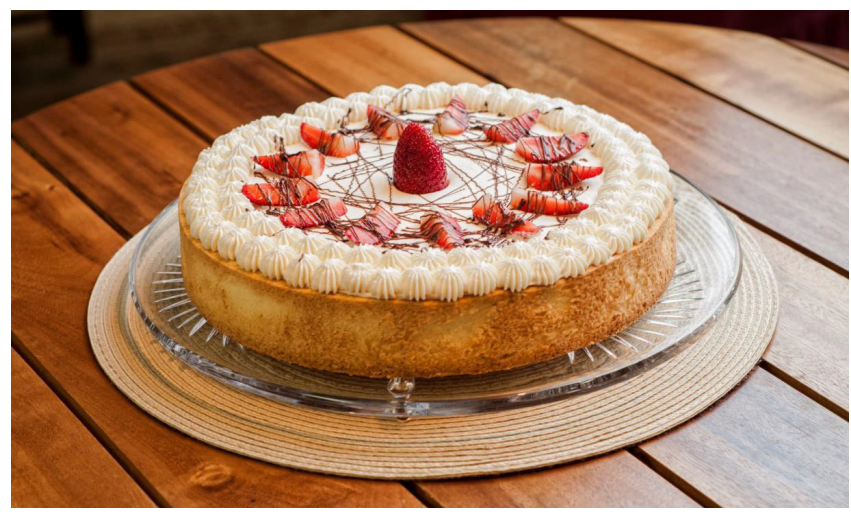

Fonte: Batista (2014).

Figura 3. Torta holandesa de chocolate com morango.

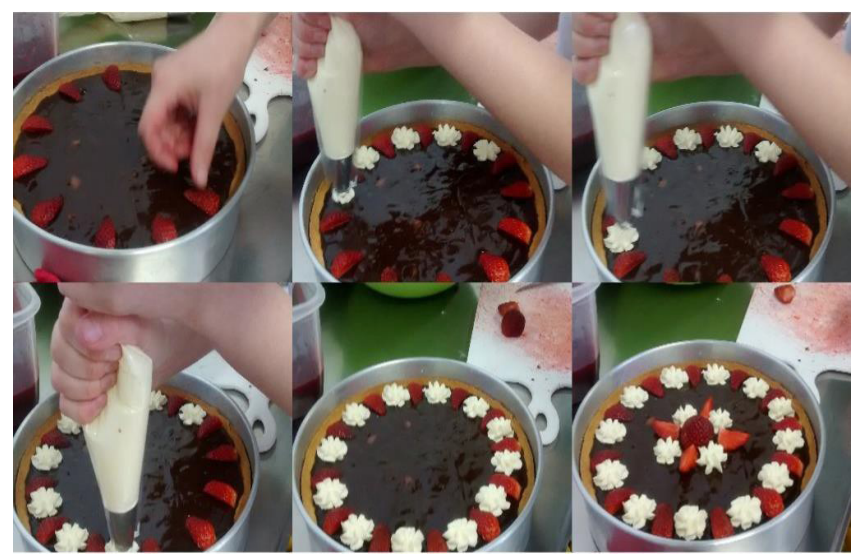

Fonte: a autora.

Conforme afirmam Pelegrini e Funari (2008, p. 80), "o preparo dos alimentos pressupõe inter-relação entre os aspectos culturais e simbólicos da vida social, entre a natureza e a cultura, entre o particular e o universal, o salgado e o doce, confirmando a legitimidade do patrimônio cultural." 
Nessa perspectiva, as tortas holandesas são um meio pelo qual os holandeses e carambeienses se identificam, principalmente, nos últimos anos com a proliferação turística dessa cidade. As famosas e deliciosas tortas holandesas caracterizaram Carambeí como a "cidade das tortas" por deter receitas centenárias, sendo um alicerce para o turismo histórico, cultural e gastronômico.

\section{REFERÊNCIAS}

CAmargo, H. L. Patrimônio histórico e cultural. São Paulo: Aleph, 2002.

CHAVES, N. B. Imigrantes - Immigranten. História da imigração holandesa na região dos Campos Gerais, 1911-2011. Perspectivas da migração holandesa no Brasil: quatro séculos de patrimônio. Ponta Grossa: Todapalavra, 2010.

DIAS, E. T. et al. Saboreando: uma forma de preservar a identidade cultural seridoense. Revista Global Tourism, [S.1.], v. 5, n. 2, p. 1-11, dez. 2009.

FIGUEIREDO, B. G. Patrimônio imaterial: saber fazer na história. In: LOUREIRO, H. M.; FIGUEIREDO, B. G. (Orgs.) Cultura e educação: parceria que faz história. Belo Horizonte: Mazza; Instituto Gultural Flávio Gutierrez, 2007. p. 46-55.

GONÇALVES, J. R. S. O patrimônio como categoria de pensamento. In: ABREU, R.; CHAGAS, M. (Orgs.) Memória e patrimônio. Rio de Janeiro: DP\&A, 2003.

HALL, S. A identidade cultural na pós-modernidade. Tradução de Tomaz Tadeu da Silva e Guacira Lopes Louro. 1. ed. Rio de Janeiro: DP\&A, 1992.
KOOY, H. A. Carambeí 75 anos: 1911-1986. Castro: Kugler, 1986.

LÉVI-STRAUSS, G. O cru e o cozido. Mitológicas 1. São Paulo: Cosac Naify, 2004.

MONTANARI, M. Comida como cultura. 2. ed. São Paulo: Senac, 2013.

PELEGRINI, S. C. A.; FUNARI, P. P. O que é patrimônio cultural imaterial? São Paulo: Brasiliense, 2008.

PEREIRA, M. A. M. Diga-me o que comes e dirte-ei quem és: Alimentação e sociabilidades culinárias na migração holandesa em Carambeí. In: II ENCONTRO DO GT REGIONAL RELIGIÃO E RELIGIOSIDADES ANPUH PR/SC. 2011. Ponta Grossa. Anais... Ponta Grossa, 201 1, p. 1137-1 157.

POSSAMAI, Z. R. Destruição legal e ilegal do patrimônio histórico. In: HEINZ, F. M.; HARRES, M. M. (Orgs.). A história e seus territórios. São Leopoldo: Oikos, 2008.

SCHLÜTER, R. G. Gastronomia e turismo. São Paulo: Aleph, 2003.

UNESCO - Organização das Nações Unidas para a Educação, a Ciência e a Cultura. Convenção para a salvaguarda do patrimônio cultural imaterial. Disponível em: <http://www. unesco.org/new/pt/brasilia/about-this-office/ single-view/news/textos_base_da_convencao_ de_2003_para_a_salvaguarda_do_patrimonio_cultural_imaterial_pdf_only/\#.U3Jrq1S5fcs>. Acesso em: 12 mar. 2014. 